\title{
BMJ Open Relations of magnesium intake to cognitive impairment and dementia among participants in the Women's Health Initiative Memory Study: a prospective cohort study
}

Kenneth Lo (1) , ${ }^{1,2}$ Qing Liu, ${ }^{2}$ Tracy Madsen, ${ }^{2,3}$ Steve Rapp, ${ }^{4}$ Jiu-Chiuan Chen, ${ }^{5}$ Marian Neuhouser, ${ }^{6}$ Aladdin Shadyab, ${ }^{7}$ Lubna Pal, ${ }^{8}$ Xiaochen Lin, ${ }^{2}$ Sally Shumaker, ${ }^{4}$ JoAnn Manson, ${ }^{9}$ Ying-Qing Feng, ${ }^{1}$ Simin Liu (i) ${ }^{2,10}$

To cite: Lo K, Liu Q,

Madsen T, et al. Relations of magnesium intake to cognitive impairment and dementia among participants in the Women's Health Initiative Memory Study: a prospective cohort study. BMJ Open 2019;9:e030052. doi:10.1136/ bmjopen-2019-030052

- Prepublication history and additional material for this paper are available online. To view, please visit the journal (http:// dx.doi.org/10.1136/bmjopen2019-030052).

Received 25 February 2019 Revised 27 August 2019 Accepted 29 August 2019

D) Check for updates

(c) Author(s) (or their employer(s)) 2019. Re-use permitted under CC BY-NC. No commercial re-use. See rights and permissions. Published by BMJ.

For numbered affiliations see end of article.

Correspondence to

Dr Kenneth Lo;

kenneth_lo@brown.edu

Dr Ying-Qing Feng; fyq1819@163.com

Professor Simin Liu; simin_liu@brown.edu

\section{ABSTRACT}

Objective To examine the associations of dietary and supplemental magnesium (Mg) as assessed by a semiquantitative food frequency questionnaire with cognitive outcomes among ageing women.

Design This work conducts a prospective cohort study of participants enrolled in the Women's Health Initiative Memory Study (WHIMS), which was subsequently extended and named WHIMS-Epidemiology of Cognitive Health.

Setting Forty clinical centres in the USA.

Participants Postmenopausal women aged $65-79$ years without dementia on enrolment.

Main outcome measures Physician-adjudicated mild cognitive impairment (MCl) and/or probable dementia (PD). Results Participants were excluded $(n=1006)$ if they had extreme values of dietary energy intake, had missing or extreme body mass index values, with prevalent $\mathrm{MCl} /$ $\mathrm{PD}$ at baseline, received only one cognitive assessment or had been followed up for $<1$ year. During $>20$ years of follow-up, 765 (11.8\%) out of 6473 participants developed $\mathrm{MCl} / \mathrm{PD}$. For MCI/PD and $\mathrm{MCl}$, the risks tended to be lower among participants in quintiles Q2-Q5 of Mg consumption compared with those in the lowest quintile. Participants in Q3 had a significantly lower risk of MCI/PD (HR 0.69, 95\% $\mathrm{Cl} 0.53$ to 0.91 ) and $\mathrm{MCl}$ (HR $0.63,95 \% \mathrm{Cl} 0.45$ to 0.87 ) after multivariate adjustments. No significant association was observed between total Mg intake and PD. The association between total $\mathrm{Mg}$ intake, $\mathrm{MCl} / \mathrm{PD}$ and $\mathrm{MCl}$ was non-linear as suggested by the likelihood test.

Conclusions Total Mg intake between the estimated average requirement and the recommended dietary allowances may associate with a lower risk of MCI/PD and $\mathrm{MCl}$.

Trial registration number NCT00685009.

\section{BACKGROUND}

Mild cognitive impairment (MCI) involves the onset and evolution of cognitive impairments beyond those expected based on an individual's age and education but not significant
Strengths and limitations of this study

- A large prospective cohort with long follow-up and careful adjudication of mild cognitive impairment/ probable dementia events to ensure a high quality of outcome assessment.

- Lacking information on serum magnesium levels in the studied population.

- The cohort included only postmenopausal women, and the findings may not be generalisable to elderly men.

enough to interfere with her or his daily activities. ${ }^{1}$ Cognitive function might decline progressively over time for people with MCI, which would impair their memory, reasoning, language and visuospatial abilities. Individuals are diagnosed with dementia when their cognitive decline interferes with their daily functions. ${ }^{2}$ Dementia affects approximately 47 million people worldwide, and its prevalence is expected to be more than triple by 2050. ${ }^{3}$ The prevalence of dementia and associated medical costs have increased dramatically in recent years in parallel with the ageing population throughout the world; this situation has increased the healthcare burden to communities, families and individuals. ${ }^{3}$ Compared with elderly men, elderly women have a higher lifetime risk for dementia ${ }^{45}$ and faster progression of cognitive impairment following diagnosis. ${ }^{6}$ Therefore, identifying the strategies for dementia prevention, particularly those that are safe, cost-effective and readily accessible to elderly women, is of both public health and clinical significance.

Magnesium (Mg) has long been thought to prevent vascular outcomes. Recent work has shown that $\mathrm{Mg}$ may regulate 
$\mathrm{N}$-methyl-D-aspartate (NMDA) receptors, which affect critical functions of the central nervous system, including neuronal development, plasticity and neurodegeneration. The NMDA receptor is permeable to calcium, sodium and potassium ions and can be blocked by $\mathrm{Mg}$ ions. ${ }^{7}$ Strong neurobiological data support the role of $\mathrm{Mg}$ intake for normal neuron functioning by helping prevent the destruction of neurons resulting from NMDA-induced excitotoxicity. ${ }^{8}$ However, few prospective studies have directly examined the relation between Mg intake (dietary and/or supplements) and the dementia risk. ${ }^{9}{ }^{10}$ We therefore conducted a prospective investigation of the role of $\mathrm{Mg}$ intake in the development of two constructs of cognitive decline, namely, MCI and probable dementia (PD), among elderly women who participated in the Women's Health Initiative Memory Study (WHIMS; 1995-2008). The participants were also followed up in the WHIMSEpidemiology of Cognitive Health Outcomes (WHIMSECHO; 2008 onwards) study.

\section{METHODS}

\section{Data source}

WHIMS is an ancillary study to the WHI Hormone Trial ( $\mathrm{n}=27347$ for the whole trial) designed to assess the effect of postmenopausal hormone therapy (HT) on dementia risk. ${ }^{11}$ Invitation to participate was sent to women in the WHI Hormone Therapy Trial; these women were aged 65-79 years and did not have dementia on enrolment. ${ }^{12}$ Following the termination of the HT intervention, WHIMS (1995-2008, 7479 participants) and subsequent WHIMS-ECHO follow-up (2008 onwards, 2900 participants) continued the annual assessments of cognitive function and adjudication of all-cause dementia and MCI status. Written informed consent was obtained from the participants.

The participants were eligible for inclusion in the present analysis if they completed the WHI Food Frequency Questionnaire (FFQ) and dietary supplement questionnaire at baseline. We further excluded women who had implausible dietary energy intake $(<600$ or $>5000 \mathrm{kcal}$ ), missing or extreme body mass index (BMI) values (BMI $<15$ or $>50 \mathrm{~kg} / \mathrm{m}^{2}$ ) and prevalent MCI $/ \mathrm{PD}$ at baseline or received only one Modified Mini-Mental State Examination (3MSE) for cognitive assessment. Lastly, to avoid reverse causation between the dietary intake and disease onset, we included only women who had been followed up for at least 1 year. The detailed participant selection is illustrated in online supplementary figure 1.

\section{Outcome variable}

The WHIMS and WHIMS-ECHO protocol used a multiphase approach to identify cases of MCI and PD. From 1995 through 2007 (WHIMS), participants were screened annually in the clinic by trained and certified examiners by using the 3MSE. The 3MSE ranges from 0 to 100 , and the initial cut-points for further testing were 72 or below for participants with $<9$ years of education and 76 or below for participants with 9 years or above of education. After 1 July 1998, the cut-points were 80 and 88 , respectively. Participants who scored below the education-adjusted 3MSE cut-points received in-depth multiphased evaluation, ${ }^{13}$ including a battery of neuropsychological tests, history and physical, neuropsychiatric evaluation and an interview with a friend or family member to assess the functional status. ${ }^{11}$

Beginning in 2008 (WHIMS-ECHO), an annual validated cognitive test battery that included the Telephone Interview for Cognitive Status-modified (TICSm) was conducted. ${ }^{14}$ Other validated tests of cognitive function were administered by telephone. ${ }^{15}$ To justify replacing the 3MSE assessment with TICSm, a validation study was performed. The results showed that the 3MSE scores predicted by TICSm was highly correlated $(0.82)$ with 3MSE scores, ${ }^{16}$ whereas the transformation of WHIMS 3MSE and WHIMS-ECHO TICSm data into relative percentile ranks fit the trajectories of global cognitive function. ${ }^{17}$ For women screened positive (ie, TICSm <31) during the WHIMS-ECHO follow-up, a reliable and preidentified informant was interviewed via telephone by using the standardised Dementia Questionnaire to assess the history of cognitive and behavioural changes, functional impairments and health events that can affect cognitive functioning. ${ }^{18}$

All available participant data in both WHIMIS and WHIMS-ECHO were submitted to a central adjudication committee at the WHIMS clinical coordinating centre. The committee had experts experienced in neurological examinations and neuropsychiatric evaluations, wherein cases are classified as no impairment, MCI or PD. ${ }^{19}$ The outcome classification was based on the Diagnostic and Statistical Manual of Mental Disorders, 4th Edition criteria for dementia ${ }^{20}$ and Petersen's MCI criteria. ${ }^{1}$

\section{Exposure variable}

The dietary $\mathrm{Mg}$ intake at baseline was derived using the baseline WHI semi-quantitative FFQ. ${ }^{21}$ The nutrient database for the WHI FFQ uses the Nutrition Data Systems for Research (NDS-R, V.2005, University of Minnesota Nutrition Coordinating Center, Minneapolis, Minnesota, USA) food and nutrient database. ${ }^{22}$ The data on the current dietary supplements at baseline were assessed by a special dietary supplement inventory interviewer-administered questionnaire. ${ }^{23}$ Participants were asked to bring all current supplements to the WHI baseline clinic visit. Staff members directly transcribed the ingredients for each supplement; the result demonstrated high correlation (ranging from 0.8 to 1.0 ) with photocopied labels in the validation study. ${ }^{24}$ Total $\mathrm{Mg}$ intake was calculated by the summation of dietary and supplemental $\mathrm{Mg}$ intake. To test the relationship between total $\mathrm{Mg}$ intake and MCI/ $\mathrm{PD}$, the $\mathrm{Mg}$ intake levels were categorised into quintiles.

\section{Covariates}

At WHI baseline, WHIMS participants completed the questionnaires on various information, including demographics 
(age and race/ethnicity), socioeconomic status (education in years), lifestyle factors (diet, smoking, alcohol use and physical activity), family or personal disease history (family history of diabetes or heart diseases, personal history of diabetes, heart diseases, cancer or related risk factors) and medication use (use of anti-inflammatory drugs, antihyperlipidaemia drugs, antidepressants, antihypertensive drugs or diuretics). Height and weight were measured at baseline to calculate the BMI.

\section{Data analysis}

Descriptive statistics were demonstrated by the quintiles of total $\mathrm{Mg}$ intake. The differences between quintiles were tested by one-way analysis of variance (ANOVA) for continuous variables and $\chi^{2}$ test for categorical variables. To examine the relationship between total $\mathrm{Mg}$ intake and incident MCI and/or $\mathrm{PD}$, Cox proportional hazards regression models were used with results presented as HRs and associated 95\% CIs. Non-cases were censored at the time of the last follow-up (WHIMS or WHIMS-ECHO), death or at the end of 2012 (the year with the most updated data from WHIMS-ECHO), whichever came first. With reference to the common analysis strategies of other WHIMS studies, ${ }^{25-27}$ the MCI/PD end point was presented as a combined end point in the primary analyses. MCI and PD were treated as secondary end points. The event time was defined as the time of screening by global cognitive tests (either 3MSE or TICSm) that triggered the subsequent workup that concluded with the central adjudication of first MCI/PD. If a participant had progressed from MCI to $\mathrm{PD}$, then she was classified as a case of PD instead of MCI. The test for linear relationship was conducted by assigning median values for quintiles and then treated it as a continuous variable in the regression model. To examine the potential non-linear relationship between the $\mathrm{Mg}$ intake (total intake or from diet only) and cognitive decline, we conducted a likelihood ratio test to compare the fit of continuous models with or without quadratic terms of $\mathrm{Mg}$ intake. A likelihood test with $\mathrm{p}<0.05$ would suggest a better fit regression model by including the quadratic term. Thus, a non-linear relationship between the $\mathrm{Mg}$ intake and cognitive outcomes was determined. To test the assumption of the Cox proportional hazards model, we examined all models by using the Schoenfeld residual test. A sensitivity analysis was performed by using dietary $\mathrm{Mg}$ intake only.

To ensure robustness of the regression analysis, we controlled for confounders with reference to previous studies on cognitive decline. Model 1 was the minimally adjusted model and included age at baseline, region in the USA, race/ethnicity, assignment arm of HT trial, BMI at baseline ${ }^{28}$ and smoking status. ${ }^{29}$ Model 2 involved covariates in model 1 plus education, ${ }^{30}$ dietary variables and physical activity (alcohol intake, energy expenditure from recreational physical activity, total intake of vitamin $\mathrm{B}_{6} / \mathrm{B}_{9} / \mathrm{B}_{12}$, total intake of calcium and vitamin $\mathrm{D}$, dietary energy in kcal), ${ }^{27}{ }^{31-34}$ the medical history and medication use (baseline self-reported status of diabetes identified by the question "Did a doctor ever say that you had sugar diabetes or high blood sugar when you were not pregnant?"), ${ }^{35}$ cardiovascular disease (including cardiac arrest, congestive heart failure, cardiac catheterisation, coronary bypass surgery, angioplasty of coronary arteries, carotid endarterectomy/angioplasty, atrial fibrillation or aortic aneurysm), ${ }^{36}$ cancer (except for skin melanoma), ${ }^{37}$ prior use of menopausal replacement therapy, ${ }^{38}$ personal history of hypertension, ${ }^{39}$ personal history of high cholesterol requiring medications, ${ }^{40}$ family medical history of diabetes, family history of heart attack or stroke and medication use (anti-inflammatory drugs, antihyperlipidaemia drugs, antidepressants, antihypertensive drugs or diuretics at baseline). ${ }^{41}{ }^{42}$ Only participants with complete data were included in each regression model. All statistical analyses were performed with R V.3.6.0. P values $<0.05$ were considered to be statistically significant.

\section{Patient and public involvement}

No patients were involved in the design of this study, in the setting of the research question or the outcome measures nor were they involved in the analysis, interpretation and writing of the results. With regard to the long follow-up period, dissemination to these groups is not applicable.

\section{RESULTS}

\section{Participant characteristics}

A total of 6473 participants were included in the analyses. The baseline characteristics of participants in WHIMS by quintiles are presented in table 1 . Women in the highest quintiles of $\mathrm{Mg}$ intake tended to have, on average, a longer time to event/censorship, greater energy expenditure from recreational physical activity and higher levels of all dietary variables as shown by one-way ANOVA. As demonstrated by the $\chi^{2}$ test, non-Hispanic white women, participants enrolled in the control group of the oestrogen+progestin trial, consumed $\geq 7$ alcohol drinks per week, with a history of cardiovascular disease, were former smokers or receiving postcollege education were more likely to have a higher level of Mg intake. The baseline characteristics of participants included $(n=6473)$ or excluded $(n=1006)$ from the analysis are compared in online supplementary table 1 . Between-group difference was significant for the majority of variables except for baseline age, recreational physical activity, total $\mathrm{B}_{6}$ and $\mathrm{B}_{12}$ intake, prevalent cancer, use of hormonal replacement therapy, treated high cholesterol and family history of diabetes/heart attack/stroke.

\section{Total magnesium intake and risk of MCI/PD}

Table 2 illustrates the association between total $\mathrm{Mg}$ intake and risk of MCI and/or PD. Five-hundred and five (7.8\%) 
Table 1 Baseline characteristics of participants in the women's health initiative memory study by quintiles of total mg intake

\begin{tabular}{|c|c|c|c|c|c|c|}
\hline & \multicolumn{6}{|l|}{ Mean (SD)/N (\%) } \\
\hline & $\begin{array}{l}\text { Q1 } \\
\text { (<197.4 mg/day) }\end{array}$ & $\begin{array}{l}\text { Q2 } \\
\text { (197.4- } \\
257.3 \mathrm{mg} / \text { day })\end{array}$ & $\begin{array}{l}\text { Q3 } \\
\text { (257.3-317.8 mg/ } \\
\text { day) }\end{array}$ & $\begin{array}{l}\text { Q4 } \\
\text { (317.8-398.7 mg/ } \\
\text { day) }\end{array}$ & $\begin{array}{l}\text { Q5 } \\
(>398.7 \mathrm{mg} / \mathrm{day})\end{array}$ & $P$ value \\
\hline Number of participants & 1294 & 1295 & 1295 & 1295 & 1294 & \\
\hline Time-to-event/censored in years & $9.1(4.4)$ & $9.6(4.3)$ & $9.9(4.3)$ & $9.8(4.3)$ & $9.7(4.4)$ & $* * *$ \\
\hline Age at baseline in years & $69.9(3.7)$ & $70.1(3.8)$ & $70.1(3.8)$ & $70.1(3.9)$ & $70.2(3.9)$ & NS \\
\hline BMI at baseline & $28.6(5.5)$ & $28.5(5.3)$ & $28.3(5.4)$ & $28.3(5.3)$ & $28.3(5.5)$ & NS \\
\hline $\begin{array}{l}\text { Recreational physical activity in MET- } \\
\text { hour }\end{array}$ & $9.4(12.4)$ & $10.5(12.2)$ & $11.2(12.9)$ & $12.3(13.2)$ & $13.3(14.9)$ & $* * *$ \\
\hline Total magnesium intake in $\mathrm{mg}$ & $153.7(29.9)$ & $228.2(17.7)$ & $287.1(17.6)$ & $355.3(23)$ & $531.1(172.3)$ & $* * *$ \\
\hline Total $\mathrm{B}_{6}$ intake in $\mathrm{mg}$ & $3.7(20.3)$ & $5.1(22.7)$ & $5.7(18.2)$ & $6.9(21.2)$ & $12.9(47.6)$ & $* \star *$ \\
\hline Total $\mathrm{B}_{9}$ intake in $\mu \mathrm{g}$ & $219.2(144.3)$ & $349.5(227.7)$ & $451.3(195.4)$ & $569.3(215)$ & $698.8(278.9)$ & $* * *$ \\
\hline Total $\mathrm{B}_{12}{ }_{12}$ intake in $\mu \mathrm{g}$ & $12(54.5)$ & $17.3(83.7)$ & $16.2(51.9)$ & $19.5(54.8)$ & $37.3(102.9)$ & $* * *$ \\
\hline Total calcium intake in $\mathrm{mg}$ & $632.9(632.6)$ & $877.6(459.3)$ & $1091.1(537.7)$ & $1335.8(566.8)$ & $1758.9(686.7)$ & $* * *$ \\
\hline Total vitamin $\mathrm{D}$ intake in $\mu \mathrm{g}$ & $3.9(3.9)$ & $6.7(4.8)$ & $9.4(5.3)$ & $11.8(5.4)$ & $15.5(7.1)$ & $* * *$ \\
\hline Dietary energy in kcal & $1080.1(306.1)$ & $1375.4(365)$ & $1589.4(444.6)$ & 1845 (537.6) & $2135.7(758)$ & $* * *$ \\
\hline \multicolumn{7}{|l|}{ Region in the USA } \\
\hline Northeast & $336(26.0 \%)$ & $377(29.1 \%)$ & $365(28.2 \%)$ & $333(25.7 \%)$ & $360(27.8 \%)$ & NS \\
\hline South & $278(21.5 \%)$ & $264(20.4 \%)$ & 255 (19.7\%) & $280(21.6 \%)$ & $238(18.4 \%)$ & \\
\hline Midwest & $310(24.0 \%)$ & $310(23.9 \%)$ & $316(24.4 \%)$ & 349 (26.9\%) & $313(24.2 \%)$ & \\
\hline West & $370(28.6 \%)$ & 344 (26.6\%) & $359(27.7 \%)$ & $333(25.7 \%)$ & $383(29.6 \%)$ & \\
\hline \multicolumn{7}{|l|}{ Race/Ethnicity } \\
\hline Non-Hispanic white & $1040(80.6 \%)$ & $1121(86.7 \%)$ & $1160(89.6 \%)$ & 1194 (92.4\%) & $1168(90.5 \%)$ & $* * *$ \\
\hline Black or African-American & 139 (10.8\%) & $94(7.3 \%)$ & $70(5.4 \%)$ & $45(3.5 \%)$ & $67(5.2 \%)$ & \\
\hline Hispanic/Latino & $52(4.0 \%)$ & $32(2.5 \%)$ & $23(1.8 \%)$ & $15(1.2 \%)$ & $22(1.7 \%)$ & \\
\hline Other & $59(4.6 \%)$ & $46(3.6 \%)$ & $41(3.2 \%)$ & $38(2.9 \%)$ & $33(2.6 \%)$ & \\
\hline \multicolumn{7}{|l|}{ HRT arm } \\
\hline E-alone & $285(22.0 \%)$ & $291(22.5 \%)$ & 247 (19.1\%) & $198(15.3 \%)$ & $227(17.5 \%)$ & $* \star *$ \\
\hline E-alone control & $286(22.1 \%)$ & $241(18.6 \%)$ & $225(17.4 \%)$ & $248(19.2 \%)$ & 257 (19.9\%) & \\
\hline $\mathrm{E}+\mathrm{P}$ intervention & $359(27.7 \%)$ & $374(28.9 \%)$ & $402(31.0 \%)$ & $414(32.0 \%)$ & $386(29.8 \%)$ & \\
\hline $\mathrm{E}+\mathrm{P}$ control & 364 (28.1\%) & $389(30 \%)$ & $421(32.5 \%)$ & $435(33.6 \%)$ & $424(32.8 \%)$ & \\
\hline 7+ alcohol drinks per week & $116(9.0 \%)$ & $151(11.7 \%)$ & $161(12.5 \%)$ & $191(14.8 \%)$ & $191(14.8 \%)$ & $* * *$ \\
\hline Prevalent diabetes & $107(8.3 \%)$ & $112(8.7 \%)$ & $92(7.1 \%)$ & $93(7.2 \%)$ & $103(8.0 \%)$ & NS \\
\hline Prevalent cardiovascular disease & 196 (15.4\%) & $236(18.5 \%)$ & $212(16.6 \%)$ & $198(15.5 \%)$ & $241(18.8 \%)$ & * \\
\hline Prevalent cancer & $54(4.2 \%)$ & $42(3.3 \%)$ & $43(3.3 \%)$ & $50(3.9 \%)$ & $43(3.3 \%)$ & NS \\
\hline HRT & & & & & & NS \\
\hline Never used & $878(67.9 \%)$ & $913(70.5 \%)$ & $885(68.3 \%)$ & 885 (68.3\%) & $883(68.2 \%)$ & \\
\hline Past user & $353(27.3 \%)$ & $318(24.6 \%)$ & 329 (25.4\%) & 334 (25.8\%) & $323(25 \%)$ & \\
\hline Current user & $63(4.9 \%)$ & $64(4.9 \%)$ & $81(6.3 \%)$ & 76 (5.9\%) & $88(6.8 \%)$ & \\
\hline Treated high cholesterol & $220(17.3 \%)$ & 239 (18.7\%) & $245(19.1 \%)$ & $222(17.4 \%)$ & 225 (17.5\%) & NS \\
\hline History of hypertension & 497 (38.9\%) & $528(41.1 \%)$ & $498(38.7 \%)$ & 455 (35.5\%) & $514(40.0 \%)$ & NS \\
\hline $\begin{array}{l}\text { Family history of diabetes, heart attack } \\
\text { or stroke }\end{array}$ & $983(76.0 \%)$ & 999 (77.1\%) & 1024 (79.1\%) & 1003 (77.5\%) & 982 (75.9\%) & NS \\
\hline Medication use $\dagger$ & 594 (45.9\%) & $610(47.1 \%)$ & $592(45.7 \%)$ & $592(45.7 \%)$ & $621(48.0 \%)$ & NS \\
\hline Smoking status & & & & & & $* * *$ \\
\hline Never smoked & 689 (53.2\%) & 691 (53.4\%) & 707 (54.6\%) & 663 (51.2\%) & 696 (53.8\%) & \\
\hline Past smoker & 488 (37.7\%) & 500 (38.6\%) & 509 (39.3\%) & $566(43.7 \%)$ & 534 (41.3\%) & \\
\hline Current smoker & 117 (9.0\%) & 104 (8.0\%) & $79(6.1 \%)$ & $66(5.1 \%)$ & $64(4.9 \%)$ & \\
\hline
\end{tabular}




\begin{tabular}{|c|c|c|c|c|c|c|}
\hline & \multicolumn{6}{|l|}{ Mean (SD)/N (\%) } \\
\hline & $\begin{array}{l}\text { Q1 } \\
\text { (<197.4 mg/day) }\end{array}$ & $\begin{array}{l}\text { Q2 } \\
\text { (197.4- } \\
257.3 \mathrm{mg} / \text { day })\end{array}$ & $\begin{array}{l}\text { Q3 } \\
(257.3-317.8 \mathrm{mg} / \\
\text { day) }\end{array}$ & $\begin{array}{l}\text { Q4 } \\
(317.8-398.7 \mathrm{mg} / \\
\text { day) }\end{array}$ & $\begin{array}{l}\text { Q5 } \\
\text { (>398.7 mg/day) }\end{array}$ & P value \\
\hline Received college education or above & $622(48.3 \%)$ & $698(54 \%)$ & 795 (61.5\%) & $817(63.1 \%)$ & $829(64.4 \%)$ & $* * *$ \\
\hline
\end{tabular}

${ }^{*} \mathrm{P}<0.05$. ${ }^{* * *} \mathrm{p}<0.001$.

†Any use of anti-inflammatory, antihyperlipidemic, antidepressant, antihypertensive or diuretic drug. Chi-squared test (categorical variables) and oneway analysis of variance (continuous variables) for subgroup differences.

E-alone, oestrogen-alone; $\mathrm{E}+\mathrm{P}$, oestrogen plus progestin; HRT, hormone replacement therapy; $\mathrm{MCI}$, mild cognitive impairment; NS, not significant; $\mathrm{PD}$, probable dementia; $\mathrm{Q}$, quintile.

women developed MCI across the increasing quintiles of total $\mathrm{Mg}$ intake, whereas 395 (6.1\%) women developed PD. When using the lowest quintile as the referent, the third quintile of total $\mathrm{Mg}$ intake was associated with the risk of composite $\mathrm{MCI} / \mathrm{PD}$ (HR $0.69,95 \% \mathrm{CI} 0.53$ to $0.91, \mathrm{p}=0.01$ ) in the fully adjusted model. Compared with the lowest quintile, the third (HR $0.63,95 \%$ CI 0.45 to $0.87, \mathrm{p}=0.01$ ), fourth (HR $0.67,95 \%$ CI 0.46 to 0.97 , $\mathrm{p}=0.04$ ) and fifth (HR $0.61,95 \%$ CI 0.39 to $0.96, \mathrm{p}=0.03$ ) quintiles were associated with a lower risk of MCI in the fully adjusted model. None of the associations between $\mathrm{Mg}$ intake (both continuous or categorical variable) and the risk of PD were significant. The test for linear relationship was not significant in all fully adjusted models (model 2). For the association of total $\mathrm{Mg}$ intake with $\mathrm{MCI} / \mathrm{PD}$ or MCI, adding the quadratic term of Mg intake to the regression model significantly improved the model fit, as shown by the likelihood ratio test (both $\mathrm{p}<0.01$ ). This result indicated a non-linear relationship between the total $\mathrm{Mg}$ intake and cognitive decline. None of the models in table 2 violated the assumption of the Cox proportional hazards model.

\section{Dietary Mg intake and risk of MCI/PD}

Table 3 illustrates the association between dietary $\mathrm{Mg}$ intake and the risk of MCI and/or PD. None of the associations between the dietary $\mathrm{Mg}$ intake (both categorical variable and the test for trend) and the risk of MCI and/ or PD were significant in the fully adjusted model (model 2 ). The test for linearity was not significant in all regression models and adding the quadratic term of $\mathrm{Mg}$ intake did not improve the model fit. None of the models in table 3 violated the assumption of the Cox proportional hazards model.

\section{DISCUSSION}

\section{Summary of findings}

We examined the association between the dietary $\mathrm{Mg}$ intake and cognitive impairment in a geographically diverse cohort of postmenopausal women in a WHI subcohort. When compared with the lowest quintile, the third quintile of total daily $\mathrm{Mg}$ intake (257.3-317.8 mg/ day) was associated with a lower risk of composite MCI/ PD and MCI after statistical adjustment for demographic characteristics, diet, lifestyle, medication use and medical history. For MCI/PD and MCI, the HR estimates in models 1 and 2 were similar in magnitude. The reduced significance in model 2 possibly being due to the increased width of the $95 \%$ CI following statistical adjustment. No association was found between Mg intake and PD. Higher $\mathrm{Mg}$ intake may be associated with a lower risk of MCI but not necessarily in a dose-response manner. The association between the total Mg intake, MCI/PD and MCI were non-linear, as suggested by the likelihood test. The $\mathrm{Mg}$ intake from only the dietary source did not significantly associate with MCI/PD, possibly because the level of $\mathrm{Mg}$ intake from diet was lower than that from diet and supplementary sources combined.

\section{Comparison with previous literature}

Our findings are consistent with those of two previous studies that demonstrated the lowest risk cognitive decline among participants with a moderate $\mathrm{Mg}$ intake. Ozawa $e t$ al assessed the association between self-reported dietary intake of minerals (potassium, calcium and $\mathrm{Mg}$ ) and dementia risk among older Japanese adults. ${ }^{9}$ The HR for the development of all-cause dementia was $0.63(95 \%$ CI 0.40 to 1.01) for the highest quartile ( $\geq 196 \mathrm{mg} /$ day) of $\mathrm{Mg}$ intake compared with the lowest quartile $(\leq 147 \mathrm{mg}$ / day). For our study, the HR for the development of PD was also not significant (HR $1.25,95 \%$ CI 0.75 to 2.08) for the highest quintile $(>398.7 \mathrm{mg} /$ day) of $\mathrm{Mg}$ intake compared with the lowest quintile $(<197.4 \mathrm{mg} /$ day $)$. In another study from the Netherlands, a U-shaped distribution in the association between the Mg levels and cognition was observed such that both low $(\leq 0.79 \mathrm{mmol} / \mathrm{L})$ levels (HR 1.32) and high ( $\geq 0.90 \mathrm{mmol} / \mathrm{L})$ serum $\mathrm{Mg}$ levels (HR 1.30) were associated with increased risk of all-cause dementia. ${ }^{43}$ For our study, compared with the lowest quintile, the second quintile of total $\mathrm{Mg}$ intake was associated with the lowest risk of combined MCI/PD and MCI after adjusting for various confounders. The present findings support the total $\mathrm{Mg}$ intake (257.3-317.8 mg/ day) between the estimated average requirement (estimated nutrient intake to meet the requirement of half of healthy individuals; $265 \mathrm{mg}$ /day for women aged $>51$ years) and recommended dietary allowances (sufficient average daily dietary intake level to meet the nutrient 
Table 2 Associations of total magnesium intake with the risk of mild cognitive impairment (MCl) and/or probable dementia (PD)

\begin{tabular}{|c|c|c|c|c|c|}
\hline & & Model $1(n=6473)$ & & Model $2(n=6183)$ & \\
\hline & Cases/Total & HR $(95 \% \mathrm{Cl}) \dagger$ & $P$ value & HR $(95 \% \mathrm{Cl}) \dagger$ & $P$ value \\
\hline $\mathrm{MCl} / \mathrm{PD}$ & & & & & \\
\hline Total magnesium intake by $\mathrm{c}$ & tiles & & & & \\
\hline Q1 (<197.4 mg/day) & $184 / 1294$ & Ref & & Ref & \\
\hline Q2 (197.4-257.3 mg/day) & $157 / 1295$ & 0.82 (0.66 to 1.02$)$ & NS & 0.86 (0.68 to 1.08$)$ & NS \\
\hline Q3 (257.3-317.8mg/day) & $134 / 1295$ & 0.65 (0.52 to 0.81$)$ & $* * *$ & 0.69 (0.53 to 0.91$)$ & * \\
\hline Q4 (317.8-398.7 mg/day) & $142 / 1295$ & 0.73 (0.59 to 0.92$)$ & * & 0.77 (0.57 to 1.05$)$ & NS \\
\hline Q5 (>398.7 mg/day) & $148 / 1294$ & 0.73 (0.59 to 0.91$)$ & * & 0.81 (0.57 to 1.17$)$ & NS \\
\hline$P$ value for trend & & & & & NS \\
\hline$P$ value for non-linearity & & & & & ** \\
\hline $\mathrm{MCl}$ & & & & & \\
\hline Total magnesium intake by 0 & tiles & & & & \\
\hline Q1 (<197.4 mg/day) & $131 / 1294$ & Ref & & Ref & \\
\hline Q2 (197.4-257.3mg/day) & $106 / 1295$ & 0.79 (0.61 to 1.02$)$ & NS & 0.77 (0.58 to 1.03$)$ & NS \\
\hline Q3 (257.3-317.8 mg/day) & $87 / 1295$ & 0.61 (0.47 to 0.81$)$ & ** & 0.63 (0.45 to 0.87$)$ & * \\
\hline Q4 (317.8-398.7 mg/day) & $91 / 1295$ & 0.71 (0.54 to 0.93$)$ & * & 0.67 (0.46 to 0.97$)$ & * \\
\hline Q5 (>398.7 mg/day) & $90 / 1294$ & 0.66 (0.50 to 0.86$)$ & $* *$ & 0.61 (0.39 to 0.96$)$ & * \\
\hline $\mathrm{P}$ value for trend & & & & & NS \\
\hline$P$ value for non-linearity & & & & & ** \\
\hline PD & & & & & \\
\hline Total magnesium intake by $\mathrm{c}$ & tiles & & & & \\
\hline Q1 (<197.4 mg/day) & $81 / 1294$ & Ref & & Ref & \\
\hline Q2 (197.4-257.3mg/day) & $77 / 1295$ & 0.89 (0.65 to 1.22$)$ & NS & 1.02 (0.73 to 1.44$)$ & NS \\
\hline Q3 (257.3-317.8 mg/day) & $72 / 1295$ & 0.76 (0.55 to 1.05$)$ & NS & 0.87 (0.60 to 1.28$)$ & NS \\
\hline Q4 (317.8-398.7 mg/day) & $80 / 1295$ & 0.86 (0.63 to 1.18$)$ & NS & 1.06 (0.69 to 1.63$)$ & NS \\
\hline Q5 (>398.7 mg/day) & $85 / 1294$ & 0.92 (0.68 to 1.26$)$ & NS & 1.25 (0.75 to 2.08$)$ & NS \\
\hline$P$ value for trend & & & & & NS \\
\hline$P$ value for non-linearity & & & & & NS \\
\hline
\end{tabular}

${ }^{*} \mathrm{P}<0.05 .{ }^{* *} \mathrm{p}<0.01,{ }^{* *} \mathrm{p}<0.001$.

†Model 1 adjustment: age at baseline, race/ethnicity, region in the USA, assignment of hormone therapy trial, BMI at baseline and smoking status.

$\ddagger$ Model 2 adjustment: covariates in model 1 along with education, alcohol intake, energy expenditure from recreational physical activity, total intake of vitamin $\mathrm{B}_{6} / \mathrm{B}_{9} / \mathrm{B}_{12}$, total intake of calcium and vitamin $\mathrm{D}$, dietary energy in kcal, baseline status of diabetes/cardiovascular disease/cancer, prior use of hormone replacement therapy, personal history of hypertension, personal history of high cholesterol requiring medications, family medical history of diabetes, family history of heart attack or stroke, use of anti-inflammatory drug, antihyperlipidaemia drug, antidepressant, antihypertensive drug or the use of diuretics at baseline.

BMI, body mass index; NS, not significant; $Q$, quintile.

requirement of $97 \%-98 \%$ healthy individuals; $320 \mathrm{mg}$ / day for women aged $>51$ years) optimal for preventing cognitive decline. ${ }^{44} 45$ Although further increment of $\mathrm{Mg}$ intake did not provide additional benefit for preventing $\mathrm{MCI} / \mathrm{PD}$, the fourth and fifth quintiles of total $\mathrm{Mg}$ intake associated with a lower MCI risk compared with the lowest quintile. Another observation is that total $\mathrm{Mg}$ intake had a similar magnitude of association with MCI/ $\mathrm{PD}$ and MCI but is associated with the risk of PD without statistical significance. In other words, total $\mathrm{Mg}$ intake is more protective against MCI. Given that we assessed the baseline diet only, the long follow-up period possibly weakened the association between the $\mathrm{Mg}$ intake and dementia.

\section{Strengths and limitations}

The strengths of the current analyses include the use of data from a large prospective cohort with long follow-up and the careful adjudication of MCI/PD events to ensure a high quality of outcome assessment. However, some limitations of assessment of $\mathrm{Mg}$ intake from dietary sources should be noted, for example, assessing the $\mathrm{Mg}$ 
Table 3 Associations of dietary magnesium intake with the risk of mild cognitive impairment (MCl) and/or probable dementia (PD)

\begin{tabular}{|c|c|c|c|c|c|}
\hline & \multirow[b]{2}{*}{ Cases/Total } & \multicolumn{2}{|l|}{ Model 1 (n=6473) } & \multicolumn{2}{|l|}{ Model 2 (n=6183) } \\
\hline & & HR $(95 \% \mathrm{Cl}) \dagger$ & $P$ value & HR (95\% Cl)‡ & $P$ value \\
\hline \multicolumn{6}{|l|}{$\mathrm{MCl} / \mathrm{PD}$} \\
\hline Q1 (<170.1 mg/day) & $168 / 1294$ & Ref & & Ref & \\
\hline Q2 (170.1-216.1 mg/day) & $160 / 1295$ & $0.93(0.75$ to 1.16$)$ & NS & 0.96 (0.76 to 1.22$)$ & NS \\
\hline Q4 (263.2-323.3 mg/day) & $144 / 1295$ & 0.79 (0.63 to 0.99$)$ & * & 0.84 (0.63 to 1.13$)$ & NS \\
\hline Q5 (>323.3 mg/day) & $149 / 1294$ & 0.81 (0.65 to 1.01$)$ & NS & 0.86 (0.59 to 1.24$)$ & NS \\
\hline$P$ value for trend & & & & & NS \\
\hline$P$ value for non-linearity & & & & & NS \\
\hline \multicolumn{6}{|l|}{$\mathrm{MCl}$} \\
\hline Q2 (170.1-216.1 mg/day) & $111 / 1295$ & 0.95 (0.73 to 1.23$)$ & NS & 0.97 (0.73 to 1.29$)$ & NS \\
\hline Q3 (216.1-263.2 mg/day) & $99 / 1295$ & $0.87(0.66$ to 1.14$)$ & NS & $0.85(0.62$ to 1.17$)$ & NS \\
\hline Q4 (263.2-323.3 mg/day) & $89 / 1295$ & 0.76 (0.57 to 1.00$)$ & NS & 0.78 (0.55 to 1.13$)$ & NS \\
\hline Q5 (>323.3 mg/day) & $88 / 1294$ & 0.73 (0.55 to 0.97$)$ & * & $0.71(0.45$ to 1.14$)$ & NS \\
\hline $\mathrm{P}$ value for trend & & & & & NS \\
\hline$P$ value for non-linearity & & & & & NS \\
\hline \multicolumn{6}{|l|}{ PD } \\
\hline \multicolumn{6}{|c|}{ Dietary magnesium intake by quintiles } \\
\hline Q1 (<170.1 mg/day) & $76 / 1294$ & Ref & & Ref & \\
\hline
\end{tabular}

${ }^{*} \mathrm{P}<0.05$.

†Model 1 adjustment: age at baseline, race/ethnicity, region in the USA, assignment of hormone therapy trial, BMI at baseline and smoking status.

$\ddagger$ Model 2 adjustment: covariates in model 1 along education, alcohol intake, energy expenditure from recreational physical activity, total intake of vitamin $\mathrm{B}_{6} / \mathrm{B}_{9} / \mathrm{B}_{12}$, total intake of calcium and vitamin $\mathrm{D}$, dietary energy in kcal, baseline status of diabetes/cardiovascular disease/cancer, prior use of hormone replacement therapy, personal history of hypertension, personal history of high cholesterol requiring medications, family medical history of diabetes, family history of heart attack or stroke, use of anti-inflammatory drug, antihyperlipidaemia drug, antidepressant, antihypertensive drug or the use of diuretics at baseline.

NS, not significant; Q, quintile.

intake at baseline only. The test based on the Schoenfeld residuals was not statistically significant. Therefore, the impact of Mg intake on MCI and/or PD was less likely to change over time. Moreover, we lack information on the serum $\mathrm{Mg}$ levels in the studied population. Despite the adjustment for dietary energy, assessment of dietary $\mathrm{Mg}$ intake can be confounded with other constituents, such as leafy green vegetables, which are the primary source of dietary $\mathrm{Mg} .{ }^{46}$ In addition, previous studies found that dietary $\mathrm{Mg}$ intake might not strongly correlate with serum Mg levels $(\mathrm{r}=0.28, \mathrm{p}<0.05) .{ }^{47}$ This condition may lead to the different magnitudes of associations, including the impact of dietary/serum Mg on the risk of a disease, such as hypertension. ${ }^{48}$ Moreover, supplemental $\mathrm{Mg}$ intake was collected for 'other supplement mixtures' and single supplements but not for standard multivitamins with minerals, the most common type of supplement used by WHI women. Although this limitation might lead to an under-ascertainment of $\mathrm{Mg}$ from supplements, whether this condition was the major flaw of this study is arguable because the total $\mathrm{Mg}$ intake demonstrated a significant association with MCI/PD. Furthermore, residual 
confounding might occur due to inaccurate measurement of some adjustment variables, such as self-reported diet and physical activity. Last but not least, the present cohort included only postmenopausal women, and the findings may not be generalisable to elderly men. Despite these limitations, this study adds important information regarding $\mathrm{Mg}$ intake for cognitive benefit in postmenopausal women.

\section{CONCLUSIONS}

Among postmenopausal women from WHIMS with over 20 years of follow-up, the total Mg intake between the estimated average requirement and recommended dietary Allowances was associated with a low risk of composite $\mathrm{MCI} / \mathrm{PD}$ and MCI but not in a dose-response manner.

\section{Author affiliations}

${ }^{1}$ Department of Cardiology, Guangdong Cardiovascular Institute, Hypertension Research Laboratory, Guangdong Provincial People's Hospital, Guangdong Provincial Key Laboratory of Coronary Heart Disease Prevention, Guangdong Academy of Medical Sciences, South China University of Technology School of Medicine, Guangzhou, China

${ }^{2}$ Centre for Global Cardiometabolic Health, Department of Epidemiology, Brown University, Providence, Rhode Island, USA

${ }^{3}$ Department of Emergency Medicine, Alpert Medical School, Brown University, Providence, Rhode Island, USA

${ }^{4}$ Wake Forest School of Medicine, Wake Forest University, Winston-Salem, North Carolina, USA

${ }^{5}$ Department of Preventive Medicine, Keck School of Medicine, University of Southern California, Los Angeles, California, USA

${ }^{6}$ Division of Public Health Sciences, Fred Hutchinson Cancer Original Research Center, Seattle, Washington, USA

${ }^{7}$ Department of Family and Preventive Medicine, University of California San Diego, La Jolla, California, USA

${ }^{8}$ School of Medicine, Yale University, New Haven, Connecticut, USA

${ }^{9}$ Division of Preventive Medicine, Department of Medicine, Brigham and Women's

Hospital, Boston, Massachusetts, USA

${ }^{10}$ Departments of Surgery and Medicine, Alpert School of Medicine, Brown University, Providence, Rhode Island, USA

Contributors KL, QL, TM, AS, LP, XL, JAM, Y-QF, SL searched the literature; analysed and interpreted the data and wrote the manuscript. SR, J-CC, MN, SS participated in the study design; collected, analysed and interpreted the data and wrote the manuscript.

Funding The Women's Health Initiative (WHI) was funded by the National Heart, Lung, and Blood Institute, National Institutes of Health and US Department of Health and Human Services through contracts HHSN268201600018C, HHSN268201600002C, HHSN268201600003C and HHSN268201600004C. The Women's Health Initiative Memory Study (WHIMS) was funded in part by Wyeth Pharmaceuticals, St. Davids, PA. The WHIMS Extension was funded by the National Institute on Aging contract HHSN26820044221C, and WHIMS-ECHO was funded by the National Institute on Aging through contracts HHSN26820044221C and HHSN271201100004C.

Disclaimer The funding sources had no role in study design, data collection, data analysis, data interpretation or the writing of this report; and in the decision to submit the manuscript for publication.

Competing interests None declared.

Patient consent for publication Not required.

Ethics approval Ethical approval of all protocols was obtained from the institutional review boards (IRBs) of all participating institutions (40 clinical site IRBs, the coordinating centre IRB and ethical review at the National Institutes of Health) (https://www.whi.org/about/SitePages/Study Organization.aspx).

Provenance and peer review Not commissioned; externally peer reviewed.
Data availability statement № data are available.

Open access This is an open access article distributed in accordance with the Creative Commons Attribution Non Commercial (CC BY-NC 4.0) license, which permits others to distribute, remix, adapt, build upon this work non-commercially, and license their derivative works on different terms, provided the original work is properly cited, appropriate credit is given, any changes made indicated, and the use is non-commercial. See: http://creativecommons.org/licenses/by-nc/4.0/.

Author note The corresponding author had full access to all the data in the study and had final responsibility for the decision to submit for publication.

\section{ORCID iDs}

Kenneth Lo http://orcid.org/0000-0003-4624-2737

Simin Liu https://orcid.org/0000-0003-2098-3844

\section{REFERENCES}

1 Petersen RC, Smith GE, Waring SC, et al. Mild cognitive impairment: clinical characterization and outcome. Arch Neurol 1999;56:303-8.

2 Arevalo-Rodriguez I, Smailagic N, Roqué I Figuls M, et al. MiniMental state examination (MMSE) for the detection of Alzheimer's disease and other dementias in people with mild cognitive impairment (MCl). Cochrane Database Syst Rev 2015:CD010783.

3 World Health Organization. The epidemiology and impact of dementia current state and future trends 2015.

4 Andersen K, Launer LJ, Dewey ME, et al. Gender differences in the incidence of $A D$ and vascular dementia: the EURODEM studies. EURODEM incidence Research Group. Neurology 1999;53:1992-7.

5 Chêne G, Beiser A, Au R, et al. Gender and incidence of dementia in the Framingham heart study from mid-adult life. Alzheimer's \& Dementia 2015;11:310-20.

6 Lin KA, Choudhury KR, Rathakrishnan BG, et al. Marked gender differences in progression of mild cognitive impairment over 8 years. Alzheimers Dement 2015;1:103-10.

7 Parsons CG, Danysz W, Quack G. Glutamate in CNS disorders as a target for drug development: an update. Drug News Perspect 1998;11:523-69.

8 Hynd M, Scott HL, Dodd PR. Glutamate-mediated excitotoxicity and neurodegeneration in Alzheimer?s disease. Neurochem Int 2004;45:583-95

9 Ozawa M, Ninomiya T, Ohara T, et al. Self-Reported dietary intake of potassium, calcium, and magnesium and risk of dementia in the Japanese: the Hisayama study. J Am Geriatr Soc 2012;60:1515-20.

10 Tzeng N-S, Chung C-H, Lin F-H, et al. Magnesium oxide use and reduced risk of dementia: a retrospective, nationwide cohort study in Taiwan. Curr Med Res Opin 2018;34:163-9.

11 Shumaker SA, Reboussin BA, Espeland MA, et al. The women's health Initiative memory study (WHIMS): a trial of the effect of estrogen therapy in preventing and slowing the progression of dementia. Control Clin Trials 1998;19:604-21.

12 Rapp SR, Espeland MA, Shumaker SA, et al. Effect of estrogen plus progestin on global cognitive function in postmenopausal women: the women's health Initiative memory study: a randomized controlled trial. JAMA 2003;289:2663-72.

13 Malouf R, Areosa Sastre A. Vitamin B12 for cognition. Cochrane Database Syst Rev 2003:CD004326.

14 Welsh KA, Breitner J, Magruder-Habib KM. Detection of dementia in the elderly using the telephone interview for cognitive status. Neuropsychiatry Neuropsychol Behav Neurol 1993;6:103-10.

15 Rapp SR, Legault C, Espeland MA, et al. Validation of a cognitive assessment battery administered over the telephone. J Am Geriatr Soc 2012;60:1616-23.10.1111/j.1532-5415.2012.04111.x

16 Arnold AM, Newman AB, Dermond N, et al. Using telephone and informant assessments to estimate missing modified Mini-Mental state exam scores and rates of cognitive decline. Neuroepidemiology 2009;33:55-65.

17 Espeland MA, Chen JC, Weitlauf J, et al. Trajectories of relative performance with 2 measures of global cognitive function. J Am Geriatr Soc 2018.

18 Ellis RJ, Jan K, Kawas C, et al. Diagnostic validity of the dementia questionnaire for Alzheimer disease. Arch Neurol 1998;55:360-5.

19 Shumaker SA, Legault C, Rapp SR, et al. Estrogen plus progestin and the incidence of dementia and mild cognitive impairment in postmenopausal women: the women's health Initiative memory study: a randomized controlled trial. JAMA 2003;289:2651-62.

20 Hogervorst E, Bandelow S, Combrinck M, et al. The validity and reliability of 6 sets of clinical criteria to classify Alzheimer's disease and vascular dementia in cases confirmed post-mortem: added 
value of a decision tree approach. Dement Geriatr Cogn Disord 2003:16:170-80.

21 Patterson RE, Kristal AR, Tinker LF, et al. Measurement characteristics of the women's health Initiative food frequency questionnaire. Ann Epidemiol 1999;9:178-87.

22 Schakel SF, Sievert YA, Buzzard IM. Sources of data for developing and maintaining a nutrient database. J Am Diet Assoc 1988;88:1268-71.

23 Neuhouser ML, Wassertheil-Smoller S, Thomson C, et al . Multivitamin use and risk of cancer and cardiovascular disease in the women's health Initiative cohorts. Arch Intern Med 2009;169:294-304.

24 Patterson RE, Levy L, Tinker LF, et al. Evaluation of a simplified vitamin supplement inventory developed for the women's health Initiative. Public Health Nutr 1999;2:273-6.

25 Ammann EM, Pottala JV, Robinson JG, et al. Erythrocyte omega-3 fatty acids are inversely associated with incident dementia: secondary analyses of longitudinal data from the women's health Initiative memory study (WHIMS). Prostaglandins Leukot Essent Fatty Acids 2017;121:68-75

26 Hayden KM, Beavers DP, Steck SE, et al. The association between an inflammatory diet and global cognitive function and incident dementia in older women: the women's health Initiative memory study. Alzheimers Dement 2017;13:1187-96.

27 Agnew-Blais JC, Wassertheil-Smoller S, Kang JH, et al. Folate, vitamin B-6, and vitamin B-12 intake and mild cognitive impairment and probable dementia in the women's health Initiative memory study. J Acad Nutr Diet 2015;115:231-41.

28 Moga DC, Abner EL, Brouwer ES. Dementia and "obesity paradox": is this for real or are we missing something? An epidemiologist's perspective. J Am Med Dir Assoc 2015;16:78-9.

29 Batty GD, Shipley MJ, Kvaavik E, et al. Biomarker assessment of tobacco smoking exposure and risk of dementia death: pooling of individual participant data from 14 cohort studies. J Epidemiol Community Health 2018;72:513-5.

30 Xu W, Tan L, Wang H-F, et al. Education and risk of dementia: doseresponse meta-analysis of prospective cohort studies. Mol Neurobiol 2016;53:3113-23.

31 Littlejohns TJ, Henley WE, Lang IA, et al. Vitamin D and the risk of dementia and Alzheimer disease. Neurology 2014;83:920-8.

32 Kern J, Kern S, Blennow K, et al. Calcium supplementation and risk of dementia in women with cerebrovascular disease. Neurology 2016;87:1674-80.

33 llomaki J, Jokanovic N, Tan E, et al. And cognitive decline: an overview of systematic reviews. Curr Clin Pharmacol 2015;10:204-12.10.2174/157488471003150820145539

34 Blondell SJ, Hammersley-Mather R, Veerman JL. Does physical activity prevent cognitive decline and dementia?: a systematic review and meta-analysis of longitudinal studies. BMC Public Health 2014; $14: 510$.

35 Espeland MA, Brinton RD, Hugenschmidt C, et al. Impact of type 2 diabetes and postmenopausal hormone therapy on incidence of cognitive impairment in older women. Diabetes Care 2015;38:2316-24.

36 Eriksson UK, Bennet AM, Gatz M, et al. Nonstroke cardiovascular disease and risk of Alzheimer disease and dementia. Alzheimer Dis Assoc Disord 2010;24:1-9.

37 Ganguli M, Cancer GM. Cancer and dementia: it's complicated. Alzheimer Dis Assoc Disord 2015;29:177-82.

38 Yaffe K, Sawaya G, Lieberburg I, et al. Estrogen therapy in postmenopausal women: effects on cognitive function and dementia. JAMA 1998;279:688-95.

39 Peters R, Beckett N, Hypertension BN. Hypertension, dementia, and antihypertensive treatment: implications for the very elderly. Curr Hypertens Rep 2009;11:277-82.

40 Reitz C. Dyslipidemia and dementia: current epidemiology, genetic evidence, and mechanisms behind the associations. J Alzheimers Dis 2012;30 Suppl 2:S127-45.

41 Jick H, Zornberg GL, Jick SS, et al. Statins and the risk of dementia. The Lancet 2000;356:1627-31.

42 Tully PJ, Hanon O, Cosh S, et al. Diuretic antihypertensive drugs and incident dementia risk: a systematic review, metaanalysis and meta-regression of prospective studies. $J$ Hypertens 2016;34:1027-35.

43 Kieboom BCT, Licher S, Wolters FJ, et al. Serum magnesium is associated with the risk of dementia. Neurology 2017;89:1716-22.

44 Bergman C, Gray-Scott D, Chen J-J, et al. What is next for the dietary reference intakes for bone metabolism related nutrients beyond calcium: phosphorus, magnesium, vitamin $\mathrm{D}$, and fluoride? Crit Rev Food Sci Nutr 2009; 49:136-44.

45 Murphy SP, Poos MI. Dietary reference intakes: summary of applications in dietary assessment. Public Health Nutr 2002;5:843-9.10.1079/PHN2002389

46 Chen GC, Koh WP, Yuan JM, et al. Green leafy and cruciferous vegetable consumption and risk of type 2 diabetes: results from the Singapore Chinese Health study and meta-analysis. Br J Nutr 2018:1-11.

47 Akizawa Y, Koizumi S, Itokawa Y, et al. Daily magnesium intake and serum magnesium concentration among Japanese people. $J$ Epidemiol 2008:18:151-9.

48 Han H, Fang X, Wei X, et al. Dose-Response relationship between dietary magnesium intake, serum magnesium concentration and risk of hypertension: a systematic review and meta-analysis of prospective cohort studies. Nutr J 2017;16:26.10.1186/s12937-0170247-4 